\title{
Assessment of Probability of Gear Tooth Side Wear of a Planetary Gearbox
}

\author{
Predrag ŽIVKOVIĆ, Milosav OGNJANOVIĆ, Ivica ČAMAGIĆ, Milivoje JOVANOVIĆ, Dragan KALABA, Radoljub TOMIĆ, Ivan GRGIĆ
}

\begin{abstract}
Gear tooth side wear in planetary gearboxes represents one of the main reasons for damage occurring in these gears. Wear magnitude is unpredictable and depends on temperature, lubrication, load, material and other random variables. Wear is a non-stationary process which is impossible to describe using a mathematical model, or to accurately assess its intensity, magnitude and distribution along the tooth sides. This paper suggests a probability assessment model for gear tooth side wear, based on experimental tests and a statistical representation of obtained results. Experimental tests of planetary gearbox gears were performed within a closed power circuit, using a previously prepared testing table, and the results of wear probability distribution were analysed. Wear probability distribution was represented using the Weibull distribution model. Obtained results of this statistical analysis have shown good compliance with the experimental ones, hence this model is applicable to all gearboxes. This method represents a considerable contribution to wear probability distribution assessment and can be used in order to assess the work life and elementary reliability of gears.
\end{abstract}

Keywords: damage; gear; probability distribution; tooth; wear

\section{INTRODUCTION}

Planetary gearboxes represent a new, modern solution for mechanical energy transmission. They are characterised by highly compact structure, high transmission ratios and high load per unit mass. They are widely applied in all types of engineering equipment, and play an important part in industrial fields such as aerospace, automotive and tool industry. The application of planetary gearboxes keeps expanding. Power transmission in these gearboxes is very specific. Part of the power is transferred by connecting, similar to a toothed connection, whereas a part of the power is transferred by coupling the teeth of coupled gears [1]. Certain phenomena, in the sense of increased sun gear, satellite gear, bevel gear and bearing wear, occur within coupled gears. The sun gear has a small radius, but is subjected to high intensity forces due to its input torque. A small number of teeth and small lateral tooth surface also contribute to increase contact stresses. The advantage is that the load acting on this gear is divided by the number of satellite gear teeth, and the forces are lower compared to same size gears that would be subjected to the total load. It is generally known that load distribution is not equal among gear teeth. Similarly, stress distribution on contact surfaces is variable, which results in tooth side wear. Wear occurs due to manufacturing inaccuracies, lubricant viscosity and/or inadequate selection and contact stress intensity, which exceed gear fatigue strength.

Gears are the most critical components in gearbox power transmission systems. A single damaged gear will lead to damage in all other components. Hence it is necessary to identify all damages that have occurred, assess their distribution and remove them. The goal of planetary gearbox gear tooth wear distribution analysis is to understand the main cause of damages in order to prevent them from occurring in the future. Wear effects lead to a change in teeth coupling speed and interaction between these teeth generates noise. In addition, increase dynamic effects decrease efficiency and can lead to catastrophic gear damage, rendering them useless. Reliable studies about tooth side wear are of great importance in order to reduce possible production losses caused by wear. Study [2] has shown that slight wear of gear side surfaces can result in changes in gear dimensions and properties. By using the micro-magnet technique for the purpose of monitoring of the grinding process, it was shown that wear has a significant effect on the quality and reliability of components [3]. Hence, reliable knowledge about the wear process in gears and other machine parts is always of great importance. Reliable assessment of wear rate and intensity was studied by numerous researchers. Experimental methods for tooth surface wear assessment are shown in [4]. This model establishes a quantitative relation between the magnitude of fatigue wear friction, load and lubrication. Numerous researchers studied wear prediction using gear and tool models which were used to aid an accurate assessment of gear wear [5-8]. Extensive research in the field of gearbox damage resulted in the DIN 3990 standard (part 5). This standard defines the procedure for durability tests of gears, with limitations related to different materials with and without heat treatment and machining. Research following this direction is continued by [9, 10], yet a number of questions in this rather complex field remain unanswered. Papers [11-16] describe wear damage, type of gear tooth wear, their interaction, occurrence and identification.

\section{PLANETARY GEARBOX USED FOR EXPERIMENTAL VERIFICATION}

A two-stage planetary gearbox was selected for the purpose of realizing the experimental tests, and its kinematic scheme can be seen in Fig. 1. It is a two-stage planetary gear with a total transmission ratio $u=42$ and nominal output shaft torque of $23000 \mathrm{~N} \cdot \mathrm{m}$. Gear parameters for each transmission level (planetary set) are shown in Tab. 1.

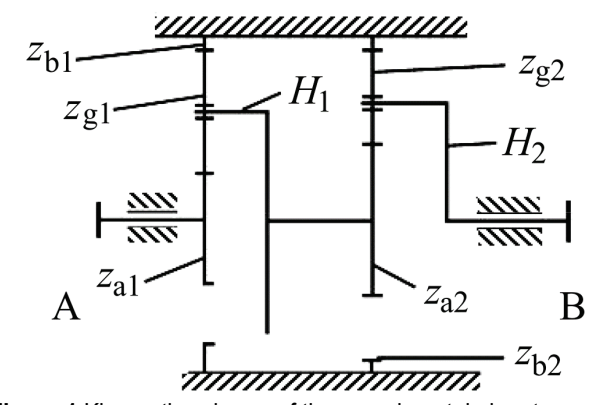

Figure 1 Kinematic scheme of the experimental planetary gear 
Table 1 Gear parameters

\begin{tabular}{|l|c|c|}
\hline \multicolumn{2}{|c|}{ EXPERIMENTAL PLANETARY GEAR } \\
\hline \multicolumn{1}{|c|}{ Planetary set } & I (A) & \\
\hline Gear module & $m_{\mathrm{n}}=3,5 \mathrm{~mm}$ & $m_{\mathrm{n}}=4 \mathrm{~mm}$ \\
\hline Number of teeth, sun gear & $z_{\mathrm{a} 1}=12$ & $z_{\mathrm{a} 1}=13$ \\
\hline Number of teeth, satellite gear & $z_{\mathrm{b} 1}=72$ & $z_{\mathrm{g} 2}=26$ \\
\hline Number of teeth, central gear with internal toothing & $T_{\mathrm{a} 1}=538 \mathrm{~N} \cdot \mathrm{m}$ & $T_{\mathrm{a} 1}=3766 \mathrm{~N} \cdot \mathrm{m}$ \\
\hline Torques & $n_{\mathrm{a} 1}=1108 \mathrm{~min}^{-1}$ & $n_{\mathrm{a} 2}=158,286 \mathrm{~min}^{-1}$ \\
\hline Rpm, sun gear & $n_{\mathrm{g} 1}=-221.6 \mathrm{~min}^{-1}$ & $n_{\mathrm{g} 1}=-39,573 \mathrm{~min}^{-1}$ \\
\hline Rpm, satellite gear & $\sigma_{\mathrm{Ha} 1}=\sigma_{\mathrm{Hg} 1}=1421 \mathrm{MPa}$ & $\sigma_{\mathrm{Ha} 2}=\sigma_{\mathrm{Hg} 2}=2412 \mathrm{MPa}$ \\
\hline Work stress on tooth side & 3 \\
\hline Number of satellite gears & 3 \\
\hline
\end{tabular}

Sun and satellite gears were made of steel $\breve{C} 4732$ 20CrMo5 (SRPS EN ISO 683-1:2018), which was heat treated and with level seven manufacturing accuracy. Bevel gears were made of steel Č4732 - 42CrMo4 (SRPS EN ISO 683-1:2018). Oil with viscosity of $41,4-50,6 \mathrm{~mm}^{2} / \mathrm{s}$ was used for lubrication and cooling of the gearbox. Gears with internal toothing were made from a single piece with a cylindrical casing. These gears thus have rigid and stable supports, while also having high stiffness themselves, and due to this, they cannot be adjusted to other gears in the coupling.

\section{TEST DISPOSITION USED IN THE EXPERIMENT}

An adequate test disposition was prepared for the experiment. This system enables measuring of the load, required rotation speed, measuring of losses, maintaining of temperature below the limit. The redactor load for long-term tests, with minimal energy consumption, was achieved using a closed power circuit principle (back to back). This system is made of two identical gearboxes with parallel shafts which have equal transmission ratios, and are connected to form a close system (Fig. 2). System load is applied via torsional elastic deforming of the shafts which connect the gearboxes. This is achieved on one of the connections which serves as the load-bearing element. Connector bolts are loosened, halves are subjected to torsion moments acting in the opposite directions, and bolts under these conditions are then tightened. The system can rotate and all of its components are subjected to this type of moment load.

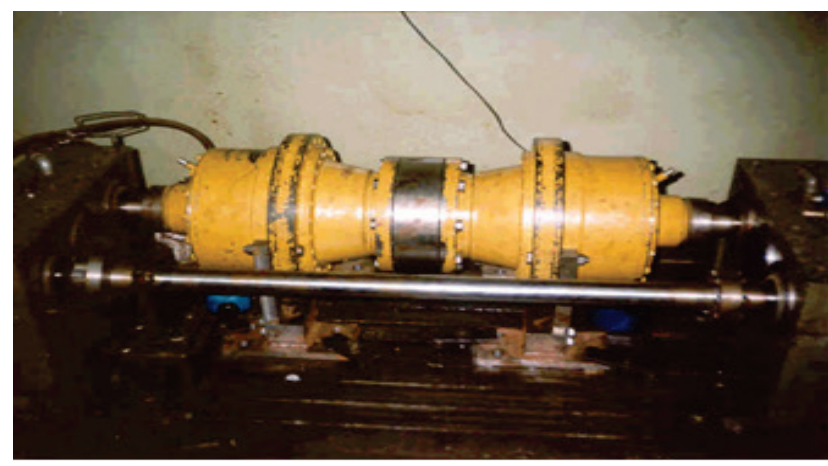

Figure 2 Coupled planetary gears in a closed power circuit

Driving electric motor had nominal power of $15 \mathrm{~kW}$, with synchronous rpm of $1500 \mathrm{~min}^{-1}$, and the moment on the load-bearing connection was $538 \mathrm{~N} \cdot \mathrm{m}$. Duration of the test was 200 hours.

\section{TEST RESULTS}

Planetary gear components are of compact structure, with high specific load-bearing capacity. Their main disadvantages are the non-uniform wear of gear tooth sides, small space for bearings a gearbox heating due to small dimensions of elements which reduce heat radiation. Non-uniform wear of gear tooth sides in a planetary gearbox will be the focus of the research presented in the following text. Fig. 3 shows wear distribution along tooth sides in planetary gearbox gears.

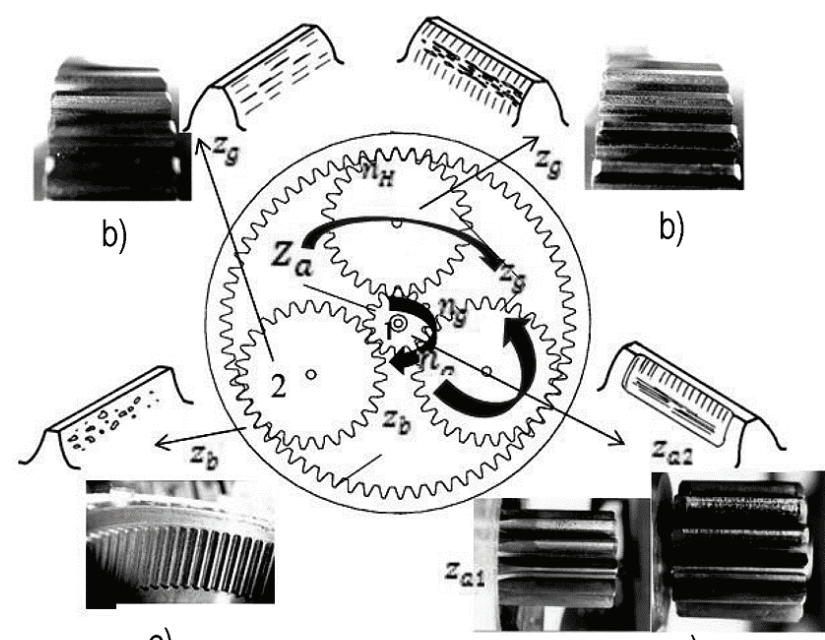

C)

a)

Figure 3 Tooth wear distribution in a planetary set a) Sun Gear, b) Planet Gear, c) Ring Gear

This was the result of experimental testing within a close power circuit on a test table, subjected to a constant moment during the test. In this structure, the sun gear (1) simultaneously achieves three teeth couplings. In addition, tooth sides of this gear are subjected to extremely high surface tension, due to their small radius. Such coupling conditions resulted in progressive wear of active tooth sides of the sun gear. Surface layer wear in the initial stage is the combination of adhesive and abrasive wear, caused by material particles separation during the starting stage, due to the absence of an oil film, and the occurrence of slight wear, as explained in more details in [13].

Fatigue wear occurs in the cases where the surfaces are constantly sliding or rolling along the same path (Fig. 6). During its work life, tooth sides in sun gears are subjected to cyclic variable loads, and variable surface pressures occur on these sides, causing surface and subsurface microcracks. In addition, macro and micro unevenness due to machining or heat treatment, contribute to the occurrence of surface micro-cracks. Cracks often propagate progressively up to a point where small pieces of materials are 
broken off at an increasing rate, and this is especially true for variable loads during exploitation. This wear mechanism is typical for gears.

This process is characteristic only for sun gears, unlike the standardised gear tooth wear models. Satellite gears are simultaneously coupled with sun gear tooth sides, as well as gears with internal toothing. First of satellite gear tooth sides which is coupled with the sun gear is subjected to surface stresses in the same way as the sun gear, however the coupling frequency (number of changes in stress) is noticeably smaller. It can be seen in Fig. 3 that the pitting in this tooth side had started in its central region. Opposite satellite gear tooth side (2) is coupled with the bevel gear with internal toothing, and is subjected to lower surface stresses due to coupling of concave and convex gears which are in contact. The number of stress changes is lower compared to the other side. This results in the initiation of micro-pitting in the tooth side, as shown in Fig. 4.

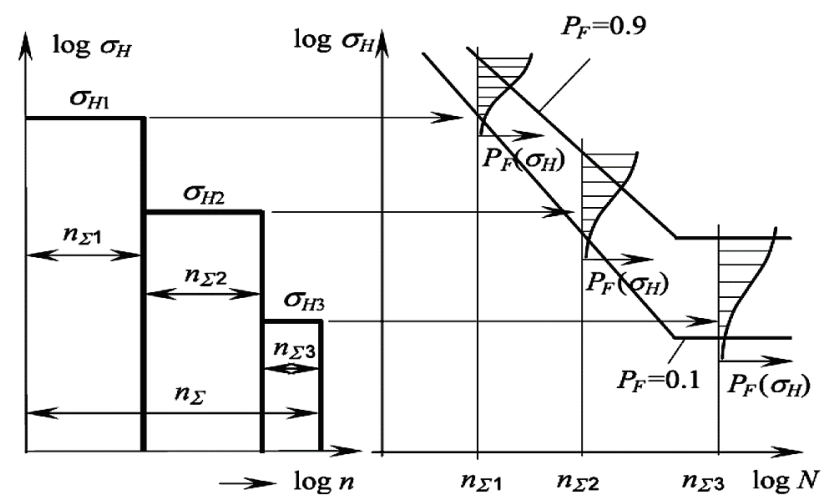

Figure 4 Ratio between work stress range and the probability of tooth side failure for gears

In addition, gear tooth sides with internal toothing are subjected to a lower number of stress changes and the wear process is not as severe initially. Smaller damage can be observed on their surfaces, caused by the penetration of particles resulting from the damage of other teeth, due to oil.

In the case of sun gear damage, all components of the planetary set are damaged as well. It is a rule that, once a single gear is damaged, it is impossible to only replace that gear, instead, it is necessary to replace everything. In the case of planetary gearboxes (Fig. 3), it is necessary to replace the whole set, once a sun gear has been damaged. Since different types of damage are possible in planetary gearboxes, and in order to prevent such damages from occurring, it is necessary to determine gear tooth side wear distribution, as well as to assess which components are the most critical. In this way, the reliability of gearboxes is increased, since it depends on the elementary reliability of components, and this is the main goal of the research presented here-to assess elementary reliability via gear tooth side wear assessment of planetary gearboxes.

In addition, working conditions more severe than the nominal ones are a possibility, including a considerably higher torque and/or rotation speeds which occur occasionally, over short time intervals. The ratios of large and small loads and rotation rates are defined using the load range, i.e. the gearbox's working mode. If it is predicted that this gearbox is used for starting construction machinery, its use will be occasional, resulting in a relatively short total working time, for example 1000 hours. If during this time different torque magnitudes are used, the load (stress) range can be represented as seen in Tab. 2, while the graphic representation is shown in Fig. 4.

Table 2 Load range for a planetary gearbox
\begin{tabular}{|c|c|c|c|c|}
\hline Level $i$ & 1 & 2 & 3 & 4 \\
\hline$T / \mathrm{N} \cdot \mathrm{m}$ & 538 & 485 & 400 & 270 \\
\hline$T /$ hours & 20 & 180 & 600 & 200 \\
\hline
\end{tabular}

Assessment of probability of damage occurring is the basis for determining of elementary reliability, and consists of the probability of occurrence of work stress and the probability of damage occurring due to this stress. Considering that during the exploitation of components, this working stress varies, damage distribution probability can be calculated as:

$F_{p}=\sum_{i=1}^{k} p_{i} \cdot P_{F i}$

where:

- $\quad$ Work stress probability:

$$
p_{i}=\frac{n \sum i}{n_{x}}
$$

- Probability of damage due to work stress:

$P_{F i}=1-\mathrm{e}^{-\left(\frac{\sigma_{\mathrm{H} i}}{\eta}\right)^{\beta}}$

- $\quad$ Stress levels: $i=1, \ldots, k$

- Weibull distribution function parameters $\eta$ and $\beta[17$, 18].

Each of the specified torques (Tab. 2) at the rpm of $1108 \mathrm{~min}^{-1}$ of the input gear, produces the corresponding stress $\sigma_{\mathrm{H}}$ with the appropriate number of changes $n_{\Sigma I}$ Damage to the flanks of the toothed gear teeth is complex, and is a combination of the processes involved. These combinations and processes are largely random in nature and can be represented by probability functions.

The Weibull distribution most frequently provides the best fit of life data. Beta-shape parameter $(\beta)$ and Scalenumber of cycles characteristic life time $(\eta)$ are the two crucial parameters of Weibull line. The slope of the line, $\beta$ is principally significant and may provide a trace to the physics of failure. The characteristic life $\eta$ is the typical time to failure in Weibull analysis $[12,17,18]$. The slope $\beta$ also indicates which class of failures is present. $\beta<1,0$ indicates infant mortality, $\beta=1,0$ means random failures (independent of age) and $\beta>1,0$ indicates wear out failures.

For a given stress level, e.g. for stress $\sigma_{\mathrm{H}}$ on tooth sides, destruction occurs for a number of $N$ tooth side couplings. Probability that the critical worn layer thickness will be reached can be represented using the Weibull function $P_{F}=1-\mathrm{e}^{-\left(\frac{N}{\eta}\right)^{\beta}}$ where $\eta$ and $\beta$ are Weibull distribution parameters. 
If a critical state of wear of tooth flanks of gears adopt worn thickness of the layer 0,3 of $m_{\mathrm{n}}$ - module gear. Then the thickness of the layer worn suits probability which is close to the unit. The zero thickness of the worn layer corresponds to a probability of zero. Since the process of surface destruction of the flanks of the teeth is long and gradual, so is the Weibull's function stretched over a large interval of the number of changes of stress, i.e. number of coupling the gear teeth.

For the stress $\sigma_{\mathrm{Ha} 1}=1421 \mathrm{MPa}$ of the sun gear of the first planetary set (Tab. 1), and the determined number of tooth couplings $n_{\Sigma \mathrm{a} 1}=60 \cdot n_{\mathrm{a} 1} \cdot t \cdot n_{\mathrm{W}}=60 \cdot 1108 \cdot 200 \cdot 3=$ $39,9 \times 10^{6}$ and the thickness of $0,2 \mathrm{~mm}$ around a worn condition (corresponding to $0,06 \times m_{\mathrm{n}}$ i.e. 0,06 of $m_{\mathrm{n}}$ module gear), estimated Weibull distribution parameters could be $\eta=2,5 \times 10^{8}$ and $\beta=1,5$; and the estimated Weibull distribution function is:

$P_{F}=1-\mathrm{e}^{-\left(\frac{N}{\eta}\right)^{\beta}}=1-\mathrm{e}^{-\left(\frac{39,9 \mathrm{e} 6}{2,5 \mathrm{e} 8}\right)^{1,5}}=0,0617$

For stress $\sigma_{\mathrm{Ha} 2}=2412 \mathrm{MPa}$ for sun gear of the second planetary set (Tab. 1), and the determined number of tooth coupling $n_{\Sigma \mathrm{a} 2}=60 \cdot n_{\mathrm{a} 2} \cdot t \cdot n_{\mathrm{W}}=60 \cdot 158,286 \cdot 200 \cdot 3=$ $5,69 \times 10^{6}$ and a thickness of the worn condition (corresponding to $0,6 \mathrm{~mm}$, i.e. 0,15 of $m_{\mathrm{n}}$ - module gear), estimated Weibull distribution parameters could be $\eta=106$ and $\beta=2$, and the estimated Weibull distribution function is

$$
P_{F}=1-\mathrm{e}^{-\left(\frac{N}{\eta}\right)^{\beta}}=1-\mathrm{e}^{-\left(\frac{5,69 \mathrm{e} 6}{10 \mathrm{e} 6}\right)^{2}}=0,2765
$$

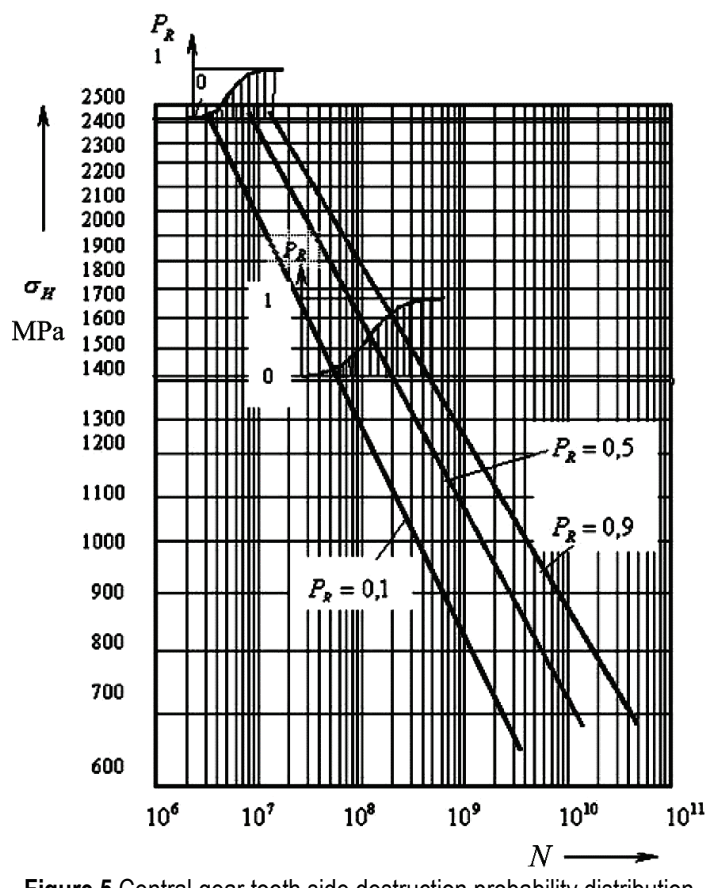

Figure 5 Central gear tooth side destruction probability distribution

Fig. 5 shows these functions for sun gears of the first and second planetary gear. Functions were drawn for stress levels corresponding to stresses in gear tooth sides during the tests. In a double logarithmic coordinate system, dynamic durability regresses to a straight line, connecting the points with equal destruction probability for both stress magnitudes. In this way, straight line corresponding to destruction probabilities $P_{R}=0,1$ and $P_{R}=0,9$, as well as the line with a probability of 0,5 . Scatter area for destruction probability was obtained based on experimental results and can be used for determining of destruction probability for any stress magnitudes that occur in exploitation, and in this way the results are transformed into working conditions.

By analysing and comparing of results obtained from the experiments (Fig. 5) and assessing the damage using the Weibull distribution, it was concluded that these results have shown good compliance. It was shown that the weakest component in the planetary gear is the sun gear of the second set. For the sun gear of the second planetary set, the stresses with their corresponding number of changes, parameters of the Weibull distribution function for probabilities of work stress and resulting destruction occurring are given in Tab. 3.

\begin{tabular}{|c|c|c|c|c|}
\hline & 1 & 2 & 3 & 4 \\
\hline$T_{\text {ula1 }} / \mathrm{N} \cdot \mathrm{m}$ & 538 & 485 & 400 & 270 \\
\hline$T_{\text {ula } 2} / \mathrm{N} \cdot \mathrm{m}$ & 3766 & 3395 & 2800 & 1890 \\
\hline$i / \mathrm{h}$ & 20 & 180 & 600 & 200 \\
\hline $\bar{J}_{\mathrm{Hi}} / \mathrm{MPa}$ & 2412 & 2290 & 2080 & 1710 \\
\hline$n_{\Sigma I}=60 \cdot n_{a 2} \cdot t \cdot n_{W}$ & $5,69 \times 10^{5}$ & $5,13 \times 10^{6}$ & $17,1 \times 10^{6}$ & $5,69 \times 10^{6}$ \\
\hline$V_{0,1}$ & $3,2459 \times 10^{6}$ & $4,2 \times 10^{6}$ & $7,1 \times 10^{6}$ & $2 \times 10^{7}$ \\
\hline$V_{0,9}$ & $1,5 \times 10^{7}$ & $1,2 \times 10^{7}$ & $3,4 \times 10^{7}$ & $1,4 \times 10^{8}$ \\
\hline$\beta_{(N)}$ & 2 & 1,94 & 1,868 & 1,585 \\
\hline & $10 \mathrm{e} 6$ & $16,268 \mathrm{e} 6$ & $23,68 \times 10^{6}$ & $82,72 \times 10^{6}$ \\
\hline${ }_{R}\left(n_{Z i}\right)$ & 0,00324 & 0,1008 & 0,419 & 0,0142 \\
\hline$P_{i}=n_{Z i} / n_{Z}$ & 0,02 & 0,18 & 0,6 & 0,2 \\
\hline$p_{i} \cdot P_{R i}$ & 0,0000648 & 0,0181 & 0,252 & 0,00279 \\
\hline
\end{tabular}

\section{VERIFICATION OF OBTAINED RESULTS}

Estimated values of shape parameter $\beta$, characteristic life-number of cycles $\eta$, period of interest, $t$ (cycles) and mean life, were determined using statistical analysis, and are given in Tab. 4 .

Table 4 Statistically determined gear parameters

\begin{tabular}{|l|c|c|}
\hline & I - planetary set & II - planetary set \\
\hline Shape parameter $(\beta)$ & 1.5 & 2 \\
\hline Chacteristic life $(\eta$, cycles) & $2.5 \mathrm{e} 8$ & $1 \mathrm{e} 7$ \\
\hline $\begin{array}{l}\text { Unreliability (probability } \\
\text { of failure) }\end{array}$ & $\begin{array}{c}0.0617 \text { at } 39.9 \mathrm{e} 6 \\
\text { cycles }\end{array}$ & $\begin{array}{c}0.2765 \text { at } 5.69 \mathrm{e} 6 \\
\text { cycles }\end{array}$ \\
\hline The reliability & $\begin{array}{c}0.9382 \text { at } 39.9 \mathrm{e} 6 \\
\text { cycles }\end{array}$ & $\begin{array}{c}0.7234 \text { at } 5,69 \mathrm{e} 6 \\
\text { cycles }\end{array}$ \\
\hline Mean life (cycles) & $225,824,000$ & $8,862,270$ \\
\hline
\end{tabular}

Calculated values, according to data from Tab. 3 are:

Probability of damage occurring in the central sun gear of the second planetary set is:

$$
\begin{aligned}
& F_{p 1}=p_{a 1} \cdot P_{p 1}+p_{a 2} \cdot P_{p 2}+p_{a 3} \cdot P_{p 3}+p_{a 4} \cdot P_{p 4}= \\
& =0,0000648+0,0181+0,252+0,00279=0,2729
\end{aligned}
$$

Reliability is equal to:

$$
P_{R}=1-F_{p i}=1-0,2729=0,7271
$$

Following results were obtained by statistical analysis: Reliability for $5,69 \times 10^{6}$ cycles was 0,72342312 (Fig. 6), as indicated by the green surface, to the right of $5,69 \times 10^{6}$ 
point, as a probability density function (PDF), shown in Fig. 7. Unreliability, i.e. failure probability was 0,27657 (Fig. 8), as indicated by the pink shaded area to the left of $5,69 \times 10^{6}$ point in the PDF area (Fig. 6), and the hazard rate, Fig. 9.

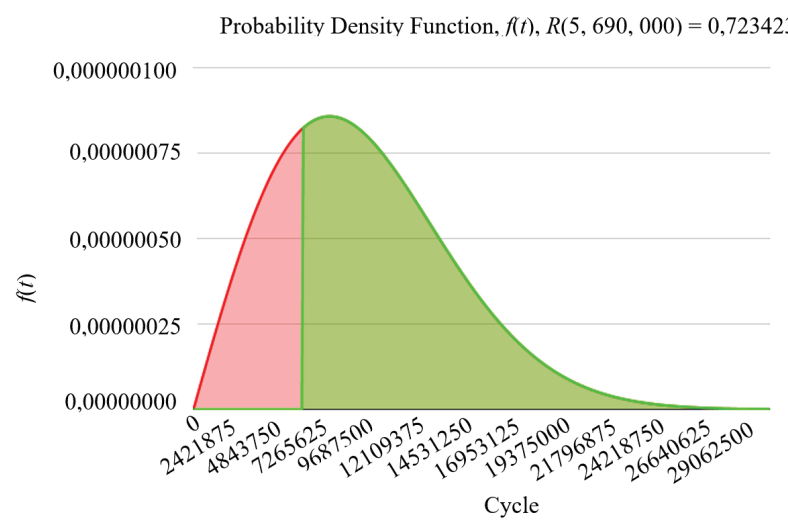

Figure 6 Probability density function [19]

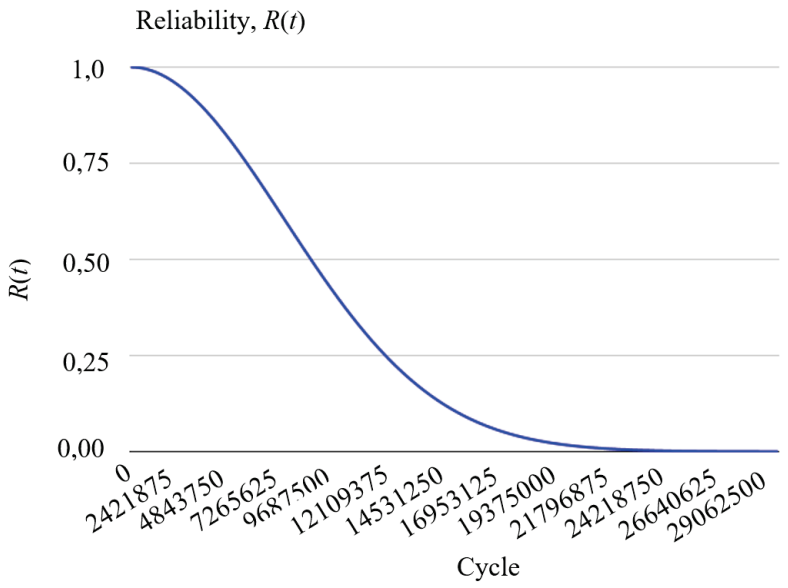

Figure 7 Reliability [19]

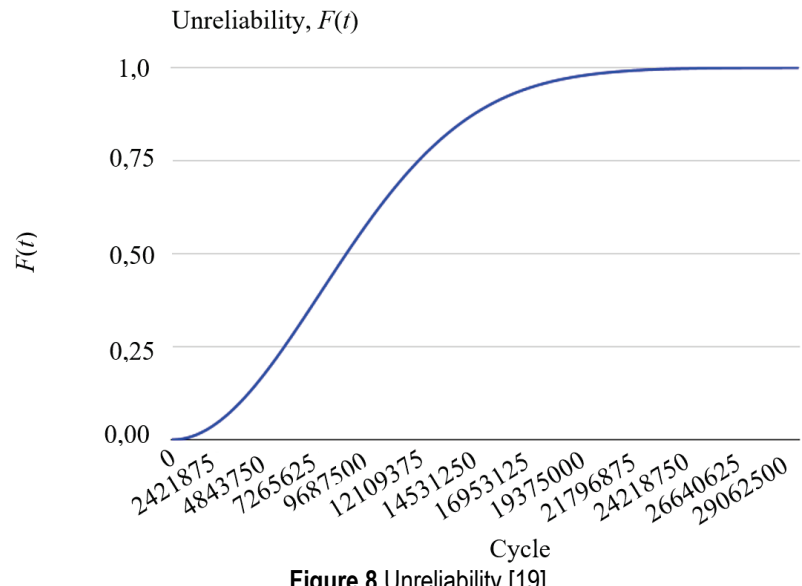

Figure 8 Unreliability [19]

Probability distribution function is proportional to the unconditional probability of damage during the time interval $t$, but it is of more use to determine how long the undamaged element lasted until this time, in terms of reliability analysis. Function $h(t)$ is referred to as the hazard rate, i.e. the current/age-specific damage rate. It describes the way in which units (tooth sides) are subjected to failureunreliable after a certain amount of time.

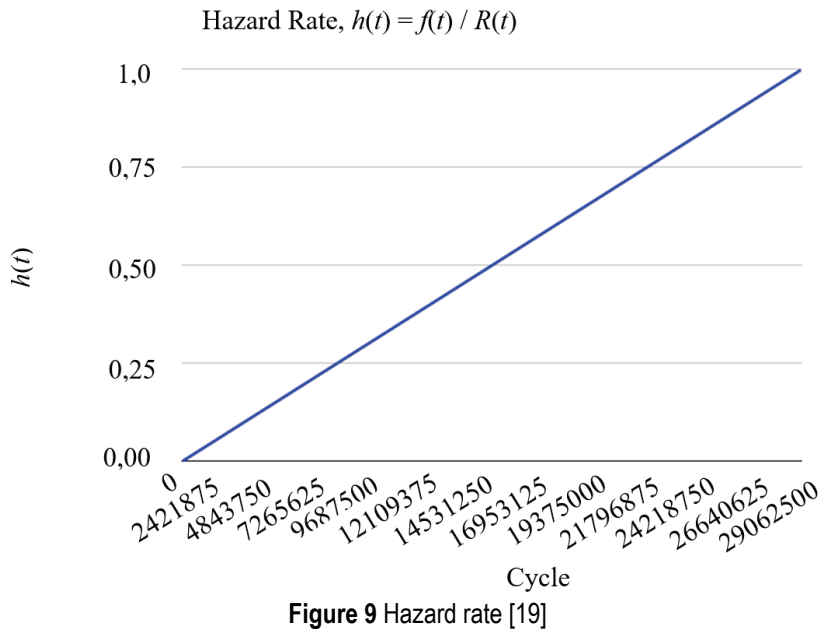

Failure / cycle:

$h_{(t)}=\frac{f(x)}{r(t)}=\left(\frac{\beta}{\eta}\right) \cdot\left(\frac{t}{\eta}\right)^{\beta-7}=\left(\frac{2}{10 \mathrm{e} 6}\right) \cdot\left(\frac{5,69 \mathrm{e} 6}{10 \mathrm{e} 6}\right)^{2-1}=$

$=1,138 \times 10$

Damage density:

$m=\frac{\beta}{\eta} \cdot\left(\frac{t}{\eta}\right)^{\beta-1} \cdot \mathrm{e}^{\left(\frac{t}{\eta}\right)^{\beta}}=\left(\frac{2}{10 \mathrm{e} 6}\right) \cdot\left(\frac{5,69 \mathrm{e} 6}{10 \mathrm{e} 6}\right)^{2-1} \cdot \mathrm{e}^{-\left(\frac{5,69 \mathrm{e} 6}{10 \mathrm{e} 6}\right)}=$
$=8,2325551 \times 10^{-8}$

Formula used to translate the hazard rate into probability is as follows:

Probability $P(t)=\frac{\text { Hazard rate } h(t)}{1+\text { Hazard rate } h(t)}$

For the presented example, the probability would be:

$P(t)=\frac{h(t)}{1+h(t)}=\frac{5,69 \times 10^{-7}}{1+5,69 \times 10^{-7}}=5,68999 \times 10^{-7}$

Reliability interval for the hazard rate is:

$p=1-P(t)=1-5,68999 \times 10^{-7}=0,99999$

Characteristic life-number of cycles $(\eta)$ is a point at which $63,2 \%$ of gear tooth sides are damaged, regardless of the shape parameters $(\beta)$. For shape parameter $\beta=2$, damage rate (hazard) increases, indicating that wear damage will occur in gear tooth sides. Assessed failure-unreliability rate is 1,138 instances of damage for every $10^{-7}$ cycles of work stress change, in gear tooth sides, and the failure density of $8,2325551 \times 10^{-7}$.

For the purpose of identifying the shape parameter and the Weibull function which best describes the set of data distribution using a single parameter, a graphical technique of showing a probability with a correlation coefficient of $0,99[20,21]$ was used and showed that the distribution function was well selected, with good result compliance 
(Fig. 10). One of the ways in which it is possible to assess how well a theoretical model describes the data distribution is by using the Q-Q graph, Fig. 11 [21].

In order to check the compatibility of a random sample with theoretical probability distribution functions, software from [21] was used, and good result compliance was observed for estimated Weibull distribution parameter values of $\eta=9855315,39$ and $\beta=2,13$, Fig. 11 .

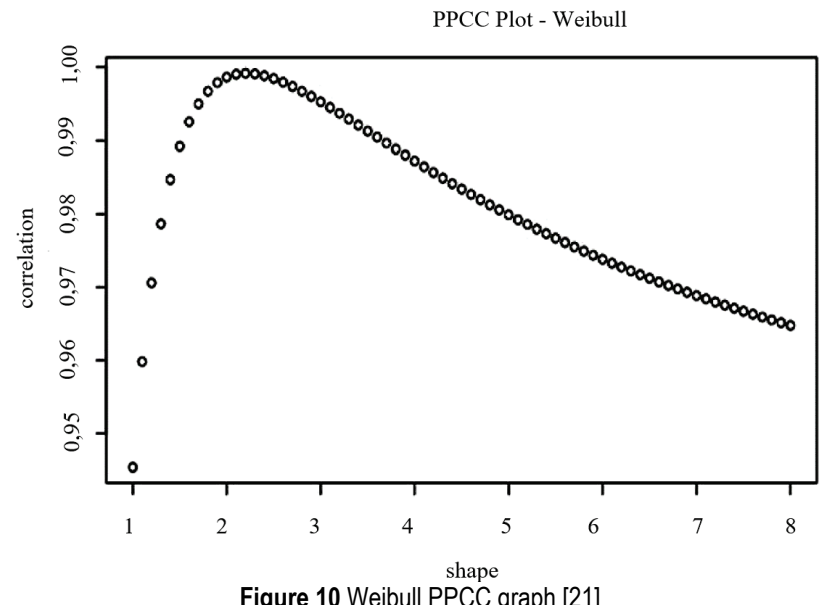

Figure 10 Weibull PPCC graph [21]

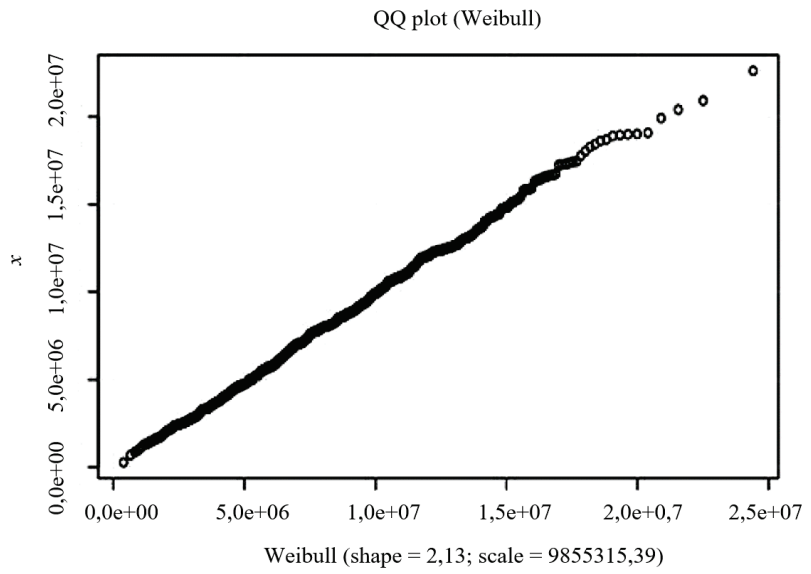

Figure 11 Weibull $Q Q$ graph [21]

\section{CONCLUSION}

Test methodology applied in this research indicated that it is possible to rationally test planetary gearbox gears, within a closed power circuit (back to back). Obtained results have shown the character of gear tooth side wear. In addition, they were represented using Weibull distribution probability function. As such, they represent a good basis for determining of elementary reliability of gears.

Destruction probability distribution for tooth sides was obtained based on tests performed for two stress levels, and can be applied to determining wear probability distribution for any stress magnitudes that may occur during exploitation. Results can be transformed into working conditions by varying the probability of work stresses occurring or the probability of gear tooth side wear. Determined mean life was 8862270 cycles. By using the hazard rate function $(h(t)$ $=1,138 \times 10^{-7}$ failure/cycles), destruction probability was determined, $P(t)=5,68999 \times 10^{-7}$, along with the reliability (confidence) interval, $p=0,99999$, for the case of damage caused by wear.
Based on the obtained values of damage probability for gear tooth sides using Weibull distribution, it was concluded that the sun gear of the second planetary set was the most critical location.

\section{Acknowledgements}

This work is a contribution to the Ministry of Education and Science of Serbia funded project TR 35006.

\section{REFERENCES}

[1] Lundvall, O. \& Klarbring, A. (2001). Simulation of wear by use of a nonsmooth Newton method-a spur gear application. Mechanics of Structures and Machines, 29(2), 223-238. https://doi.org/10.1081/SME-100104481

[2] Tönshoff, H. K., Karpuschewski, B., \& Regent, C. (1999). Process monitoring in grinding using micromagnetic techniques. International Journal of Advanced Manufacturing Technology, 15(10), 694-698. https://doi.org/10.1007/ s001700050121

[3] Wang S, Yan Y, Yin W, et al. (2008). Calculation model of fatigue wear-off in gear engagement. Journal of Northeastern University (Natural Science), 29: 1164-1167. ISSN: 1005-3026

[4] Twardowski P, Legutko S, Krolczyk GM, et al. (2015). Investigation of wear and tool life of coated carbide and cubic boron nitride cutting tools in high speed milling. $A d v$ Mech Eng, 7: 1-9. https://doi.org/10.1177/1687814015590216

[5] Bravo, A., Koffi, D., Toubal, L., \& Erchiqui, F. (2015). Life and damage mode modeling applied to plastic gears. Engineering Failure Analysis, 58(P1), 113-133. https:// doi.org/10.1016/j.engfailanal.2015.08.040

[6] Tong, D., Gu, J., \& Totten, G. E. (2018). Numerical investigation of asynchronous dual-frequency induction hardening of spur gear. International Journal of Mechanical Sciences, 142-143, 1-9. https://doi.org/10.1016/j.jimecsci. 2018.04.036

[7] Olsson, E., Olander, A., \& Öberg, M. (2016). Fatigue of gears in the finite life regime - Experiments and probabilistic modelling. Engineering Failure Analysis, 62, 276-286. https://doi.org/10.1016/j.engfailanal.2016.01.012

[8] Hohn B. R. \& Winter H. (1997), Laboratories at Work: Institute for Machine Elements, Gear Research Centre (FZG). Tribology journal, 3-3, 325-340, ISSN: 1023-8883. https://doi.org/10.1002/tt.3020030306

[9] Hohn, B. R. (2002), Modern Gear Calculation. Proceedings of the International Conference on Gears, VDI-Berichte $1665,23-43$.

[10] Ognjanovic, M. (2008). Failure Probability of Gear Teeth Wear, in: Fracture of Nano and Engineering Materials and Structures. Springer Netherlands, 1059-1060. https://doi.org/ 10.1007/1-4020-4972-2_525

[11] Ognjanovic, M. (2004). Progressive gear teeth wear and failure probability modeling. Tribology in Industry, 26(3-4), 44-49.

[12] Borror, C. M. (2018). Miller and Freund's Probability and Statistics for Engineers, 6th Ed. Journal of Quality Technology, 33(1),122-122. https://doi.org/10.1080/0022 4065.2001.11980057

[13] Tomic, R. (2019). Influence of tribological pairs on structural and material damage. Structural integrity and life, 19(1), 58-66.

[14] Gołębski, R. \& Szarek, A. (2019). Diagnosis of the Operational Gear Wheel Wear. Tehnički vjesnik, 26(3), 658661. https://doi.org/10.17559/TV-20180321171428

[15] Gołębski, R. \& Ivandić, Ž. (2018). Analysis of Modification of Spur Gear Profile. Tehnički vjesnik, 25(2), 643-648. 
https://doi.org/10.17559/TV-20171018100732

[16] Nieszporek, T., Gołębski, R., \& Šooš, L. (2017). Analysis of the wormwheel toothing accuracy. Tehnički vjesnik, 24(4), 993-1000. https://doi.org/10.17559/TV-20160422094400

[17] Lai, C.-D., Murthy, D. N., \& Xie, M. (2007). Weibull Distributions and Their Applications. In Springer Handbook of Engineering Statistics, 63-78. https://doi.org/10.1007/978-1-84628-288-1_3

[18] Abernethy, R. B. (2000). The new Weibull handbook: Reliability \& statistical analysis for predicting life, safety, surviva-bility, risk, cost and warranty claims. North Palm Beach, Fla: R.B. Abernethy.

[19] http://www.mathwave.com/

[20] Filliben, J. J. (1975), The Probability Plot Correlation Coefficient Test for Normality. Technometrics, 111-117. https://doi.org/10.1080/00401706.1975.10489279

[21] Wessa, P. (2019). Free Statistics Software, Office for Research Development and Education, version 1.2.1, URL https://www.wessa.net/

\section{Contact information:}

\section{Predrag ŽıVKOVIĆ,}

(Corresponding author)

Faculty of Technical Sciences,

7 Kneza Miloša street, K. Mitrovica, Serbia

\section{Milosav OGNJANOVIC}

Faculty of Mechanical Engineering

16 Kraljice Marije street, Belgrade, Serbia

E-mail: mognjanovic@mas.bg.ac.rs

\section{Ivica ČAMAGIĆ}

Faculty of Technical Sciences,

7 Kneza Miloša street, K. Mitrovica, Serbia

E-Mail: Ivica.camagic@pr.ac.rs

\section{Milivoje JOVANOVIĆ,}

Faculty of Technical Sciences,

7 Kneza Miloša street, K. Mitrovica, Serbia

\section{Dragan KALABA,}

Faculty of Technical Sciences,

7 Kneza Miloša street, K. Mitrovica, Serbia

\section{Radoljub TOMIĆ,}

Faculty of Strategic and Operational Management

University Union,

Staro sajmiste bb, Belgrade, Serbia

\section{Ivan GRGIĆ,}

Josip Juraj Strossmayer University of Osijek,

Mechanical Engineering Faculty in Slavonski Brod,

Trg Ivane Brlić-Mažuranić 2

HR-35000 Slavonski Brod, Croatia

E-mail: igrgic@sfsb.h 